\title{
O LEGADO HISTÓRICO DA REVOLUÇÃO RUSSA E A ATUALIDADE DE SEUS FUNDAMENTOS TEÓRICOS E POLÍTIÇOS
}

\section{THE HISTORICAL LEGACY OF THE RUSSIAN REVOLUTION AND THE CURRENT OF THEIR THEORETICAL AND POLITICAL FOUNDATIONS}

Alisson Slider do Nascimento de Paula ${ }^{1}$

Emmanoel Lima Ferreira ${ }^{2}$

Kátia Regina Rodrigues Lima ${ }^{3}$

RESUMO

Frederico Jorge Ferreira Costa ${ }^{4}$

O artigo busca analisar os aspectos históricos da Revolução Russa e a atualidade de seus fundamentos teóricos e políticos. Trata-se de uma pesquisa de natureza bibliográfica onde optou-se por utilizar clássicos do marxismo para apreciar o presente objeto, isto é, a Revolução Russa, nesse sentido, o texto desdobra-se como descritivo. O legado da Revolução de Outubro foi a URSS impedir o nazismo de vencer a guerra e o mundo se tornar um imenso campo de concentração. A ameaça vermelha obrigou a burguesia europeia a criar o Estado do Bem EstarSocial. A Revolução de 1917 ensina para a América Latina que abandonar os objetivos socialistas acaba levando ao abandono, inclusive, das bandeiras democráticas e que, somente um governo dos trabalhadores expropriando a burguesia poderá realizar a contento essas bandeiras.

PALAVRAS-CHAVE: Revolução Russa; Crise do Capitalismo; Partido e Revolução.

\begin{abstract}
The article seeks to analyze the historical aspects of the Russian Revolution and the actuality of its theoretical and political foundations. It is a research of a bibliographic nature where it was chosen to use classics of Marxism to appreciate the present object, that is to say, the Russian Revolution, in this sense, the text unfolds as descriptive. The legacy of the October Revolution was the USSR to prevent Nazism from winning the war and the world to become a huge concentration camp. The red threat forced the European bourgeoisie to create the welfare state. The Revolution of 1917 teaches for Latin America that abandoning socialist objectives ends up leading to the abandonment of even the democratic flags and that only a government of the workers expropriating the bourgeoisie can happily carry out these banners.
\end{abstract}

KEYWORDS: Russian Revolution. Crisis of Capitalism. Party and Revolution.

\footnotetext{
${ }^{1}$ Doutorando pelo Programa de Pós-Graduação em Educação da Universidade Estadual do Ceará (PPGE-UECE). Integrante do Grupo de Pesquisa em Ontologia do Ser Social, História, Educação e Emancipação Humana (GPOSSHE). Professor do curso de Educação Física do Instituto Superior de Teologia Aplicada (INTA).

${ }^{2}$ Doutor em Sociologia pela Universidade Federal do Ceará. Professor da Universidade Regional do Cariri (URCA).

${ }_{3}^{3}$ Doutora em Educação pela Universidade Federal de São Carlos (UFSCar). Professora da Universidade Regional do Cariri (URCA).

${ }^{44}$ Doutor em Educação pela Universidade Federal do Ceará, professor na Faculdade de Educação de Itapipoca da Universidade Estadual do Ceará, pesquisador colaborador do Instituto de Estudos e Pesquisas do Movimento Operário (IMO/UECE). Coordenador do Grupo de Pesquisa em Ontologia do Ser Social, História, Educação e Emancipação Humana (GPOSSHE).
} 


\section{INTRODUÇÃO}

Escrever sobre a revolução de 1917 pode parecer anacrônico ou saudosismo incurável daqueles que não se curvam ao suposto fim do ciclo da revolução russa, o breve século XX. O horizonte que estaria colocado para os trabalhadores seria lutar por reformas no marco do capitalismo, defender regulações e políticas distributivas, políticas anticíclicas, ou seja, retomar o keynesianismo ou formular um neokeynesianismo. De nossa parte entendemos que conceber tal alternativa é propor atacar moinhos de ventos. A crise de 2007-2008 pôs por terra as ilusões de um capitalismo mundializado e a abertura de um novo ciclo semelhante ou superior aos trinta anos gloriosos. O que ocorreu de fato foram períodos de maior instabilidade, consolidação do enfraquecimento da hegemonia norte-americana a tal ponto que nas eleições estadunidense o candidato eleito não era o favorito de seu partido e nem o candidato do establisment estadunidense, Wall Strett e o complexo industrial militar. A eleição de Trump denota a crise sob a qual está mergulhada a economia dos Estados Unidos e a economia internacional.

Os trilhões de dólares injetados para impedir o alastramento da crise e de seus efeitos não relançaram a economia para novo ciclo expansivo. A tese neoliberal de um capitalismo imune a crises, como a de 1929, mostrou que era uma política para recuperar o espaço perdido pelo capital nos países periféricos, nos países centrais e jogar o ônus da crise nas costas da classe trabalhadora. Os fatores que levaram a crise mundial continuam presentes tais como, a enorme massa de capital especulativo sem contrapartida no setor produtivo, baixas taxas de investimentos, queda da taxa de lucro, superprodução de capitais e anarquia da produção. Não houve sequer algo semelhante a Glass Steagall act, implementada por Roosevelt, separando bancos comerciais e bancos de investimentos e, regulamentando fortemente o setor financeiro. A ideia de que os países periféricos seriam o motor da retomada do crescimento também se esvaiu com a crise se abatendo sobre os Brics.

Nesse sentido escrever sobre a revolução russa de 1917, não é como visitar um museu de coisas mortas de um passado longínquo, parafraseando Marx: de te fabula narratur. A crise atual coloca mais presente do que nunca a disjuntiva de Rosa Luxemburgo, socialismo ou barbárie.

Em acréscimo, a presente pesquisa objetiva analisar os aspectos históricos da Revolução Russa destacando sua relevância e atualidade de seus fundamentos teóricos e políticos. A investigação inscreve-se nos marcos da pesquisa de natureza bibliográfica onde optou-se por utilizar clássicos do marxismo para apreciar o presente objeto, isto é, a Revolução 
Russa, nesse sentido, o texto desdobra-se como descritivo. No limite, com o bicentenário de Marx e em tempos de contraofensiva ultraconservadora é crucial investigar a experiência Russa com os bolcheviques e o movimento da revolução socialista.

\section{O CENTENÁRIO DA REVOLUÇÃO RUSSA, SUA VIGÊNCIA E A CRISE ATUAL DO CAPITALISMO}

Gramsci (2004) escreveu que a Revolução Russa foi contra o capital, não o dos capitalistas, mas o capital de Marx, que tinha se tornado na Rússia, nas mãos da socialdemocracia, uma teoria evolucionista pelo fato da socialdemocracia prescrever que a revolução deveria passar: primeiro, pelas dores do parto do capitalismo para depois, em outra etapa histórica, possibilitar a ruptura com o capitalismo, ou seja, o marxismo teria se transformado num dogma, numa nova escolástica.

Gramsci (2004) estava certíssimo ao fazer tal declaração. Trotsky e Lenin foram hereges que romperam com o pensamento reinante. O capital na Rússia pela leitura dos mencheviques e do "pai" do marxismo russo, Plekanov colocava a teoria marxista numa espécie de leito de procusto da revolução democrática, ou seja, do seguidismo à burguesia. Lenin e Trotsky agiram como heresiarcas porque romperam com a tese de que a Rússia não estava madura para a Revolução socialista.

Trotsky (1977) rompeu com a ideia que inclusive estava presente em Marx: tal amo tal servo, ou seja, que os países avançados espelhavam o futuro para os países retardatários. Defendeu que as tarefas da revolução eram democráticas, mas a força social que levaria a cabo estas tarefas era o proletariado concentrado nas plantas industriais. A burguesia russa, devido à escassez de poupança interna e grande parte do orçamento do país ter sido carreado para a máquina de Estado czarista se aliou ao capital estrangeiro para promover a industrialização que por sua vez interessava ao czarismo como forma de se defender das potências internacionais que cobiçavam o lebensraum russo e como forma de projetar seu poder internacionalmente, como ocorreu na guerra da Criméia e na Guerra russo-japonesa de 1905 que deixou patente o atraso russo frente ao Japão.

Lenin (1978) também foi heresiarca porque teve que reformular suas concepções estratégicas ao voltar do exílio da Suíça e desembarcar na famosa estação Finlândia, em Petrogrado, e espantar seus correligionários, da direção do partido, que consideravam que Lenin tinha virado anarquista ou adepto de Trotsky ao defender, nas Teses de Abril, que o caráter da revolução na Rússia era socialista. 
Marx (2011), na revolução de 1848, considerava que a Rússia era o esteio da contrarrevolução internacional e que só haveria transformações, nesse país, vinda de fora como uma guerra que derrocasse o czarismo, por exemplo. Mas ao se corresponder com jovens revolucionários russos que lutavam contra a autocracia czarista e seu cortejo, começou a mudar de ideia e vislumbrou que a comuna aldeã poderia ser um ponto de apoio se houvesse uma revolução democrática na Rússia combinada com uma revolução internacional. Independente se foi ou não um expediente tático para abrir diálogo promissor com jovens, que sofriam perseguições e arriscavam a pele na luta contra a autocracia, e aproximá-los das posições de Marx, tal atitude já demonstra o seu espirito aberto. Marx disse que não escreveu uma filosofia da história, mas sobre o desenvolvimento do capitalismo na Europa Ocidental e, que, não obrigatoriamente outros países iriam seguir a mesma senda.

Samir Amin com muita propriedade disse que o capitalismo nasce globalizado e é a pura verdade, e nasce também eivado de contradições $\mathrm{O}$ capitalismo é marcado com crises recorrentes. O fato de separar produção da venda, a anarquia da produção, a socialização cada vez maior do trabalho e a apropriação cada vez mais privada torna esse regime social muito mais instável que os modos de produção pré-capitalistas. Para Marx e Engels (2007) quanto mais capitalismo, maior a possiblidade de crises, aumento da composição orgânica do capital, queda tendencial da taxa de lucro etc. As crises são momentos de explosões dessas contradições.

Amin $(2004$, p. 73$)$ vê o processo de expansão do capitalismo como criação de centros e periferias.

A análise que proponho inscreve-se numa visão histórica geral da expansão do capitalismo, que não vou desenvolver aqui por razões de espaço. Nessa visão, o capitalismo foi sempre, desde suas origens, um sistema polarizador por natureza, ou seja, imperialista. Esta polarização — quer dizer, a construção concomitante de centros dominantes e periferias dominadas e sua reprodução mais profunda em cada etapa - é própria do processo de acumulação do capital operante em escala mundial, fundado sobre o que chamei de "a lei do valor mundializada".

A revolução russa foi plasmada pela crise sistêmica que pôs fỉm a visão idílica da Belle Époque que gerou nas direções dos partidos socialdemocratas a ideia de desenvolvimento linear e de progresso do capitalismo, anulando as crises ou amenizando-as Daí estes setores postularem que as leis extraídas por Marx de seus estudos, sobre as tendências fundamentais da economia capitalista e suas crises recorrentes, estavam equivocadas. Foi rechaçada a teoria da crise, a pauperização crescente da classe trabalhadora, a dialética, a ideia de que o capitalismo criava o espaço histórico para a transição socialista por meio das lutas de classes e da ditadura do proletariado. Bernstein foi o maior expoente dessa perspectiva gerada pela expansão 
acelerada do capitalismo e do relativo desenvolvimento pacífico desse regime social e, da ausência de guerras entre as grandes potências europeias, excetuando a Guerra da Criméia.

A fase imperialista que se dá no final do século XIX, após a crise de 1873 até 1895 , que foi considerada a Grande Depressão do século XIX, vai ver o nascimento do fim de uma Era - a do capitalismo de livre concorrência - e a passagem para a fase de monopolização da economia — com trustes e cartéis comandando a economia — , fase também de acirramento da luta entre os países para redesenhar o mundo a seu favor com o surgimento de novas potências industriais, ou seja, de disputas interimperialistas; da escalada militarista; da opressão de países centrais sobre os países periféricos; da prevalência das exportações de capitais sobre as exportações de mercadorias; da fusão do capital bancário com o capital industrial, gerando o capital financeiro.

A fase que se encerra deixa ensinamentos estratégicos importantes, dentre eles: que a separação por meio de uma muralha da China entre o programa mínimo — das reformas nos marcos do capitalismo - e das tarefas da revolução socialista - socialização dos meios de produção e expropriação da burguesia - da fase do capitalismo de livre concorrência havia definitivamente ficado para trás. Daí Lenin ter dito que se rompeu o elo mais débil da cadeia porque a revolução estava na ordem do dia.

Os liberais viam a URSS como uma aberração histórica não só porque rompeu com o sacrossanto mercado e suas leis de bronze, mas porque os bolcheviques levariam a URSS a uma jaula de ferro porque a nacionalização e estatização dos meios de produção iriam criar um leviatã ao invés de instaurar uma Era de emancipação. Weber não teve nenhum prurido ao vociferar contra Karl Liebknecht e Rosa Luxemburgo na revolução fracassada de 1918 quando foram assassinados pelas tropas protofascistas, a soldo do governo social democrata de Ebert e de seu ministro da defesa, também socialdemocrata. Weber (1973) dizia que a revolução russa criaria uma ditadura dos cabos e por ironia da história, a ditadura de um cabo não foi na URSS, mas na Alemanha. Com isso não estamos querendo dizer que Weber era fascista, muito pelo contrário, era um liberal, mas um liberal nacionalista que pensava na projeção de seu país na arena da luta de classes.

O instinto e a visão de mundo de classe falam mais alto nos grandes momentos históricos. Não foi à toa que Durkheim e Weber, de seus respectivos países, saudaram a Primeira Guerra Mundial pelo fervor patriótico desencadeado. Já Lenin e Trotsky e outros dirigentes como Jaures, na França, ficaram espantados como a classe trabalhadora estava sendo levada por seus líderes a posições nacionalistas e chauvinistas extremadas. Jaures foi 
assassinado por um nacionalista. Os dois revolucionários russos, que sabiam que a Guerra na verdade era uma forma do capitalismo resolver suas crises, mas que a velha toupeira estava agindo socavando os alicerces dos governos, dos Impérios, das direções tradicionais do movimento dos trabalhadores e abrindo o espaço para a revolução socialista internacionalista, mantiveram sua fé no internacionalismo e na revolução socialista. Não no sentido religioso, mas do estudo das tendências fundamentais do capitalismo que apontavam que uma Era de revoluções se aproximava.

Marx e Engels (2007), no Manifesto escrito para a Liga dos Comunistas, escreveu que o capitalismo tem três formas de resolver suas crises: a exploração mais intensa de mercados antigos, a abertura de mercados novos, e as guerras. A revolução russa se inscreve dentro desse marco.

Las relaciones burguesas resultan demasiado estrechas para contener las riquezas creadas em su seno. ?Como vence esta crisis la burguesía? De una parte, por la destrucción obligada de una massa de fuerzas productivas; de outra, por la conquista de nuevos mercados y la explotación más intensa de los antigos? De quê modo lo hace, pues? Preparando crisis más extensas y más violentas y disminuyendo los médios de prevenirlas. (MARX; ENGELS, 2007, p.30).

O capitalismo na Rússia se desenvolvia a passos largos após a Guerra da Crimeia e da emancipação dos servos. O capital estrangeiro, belga, francês e alemão aportaram em busca de lucros. Fábricas, ferrovias, mercadorias iam surgindo modificando a idiotia do mundo rural russo e novas ideias aportavam no Império. Os primeiros marxistas russos foram narodniks que fizeram um balanço de suas teorias e formas de lutas. Encontraram no marxismo uma arma mais afiada para enfrentar o czarismo e as tarefas da revolução que eram a derrubada da autocracia, a reforma agrária, a industrialização do país, a independência nacional etc.

A entrada da Rússia na Primeira Guerra apenas acentuou a decrepitude e inépcia do czarismo. Os soldados iam lutar sem armamento e vestimenta adequados. O Czar colocara a Rússia na guerra para tentar exorcizar a revolução e para manter seus acordos secretos que o prendia à Tríplice Entente, no plano econômico, militar e político.

Milhões de camponeses armados e jogados no torvelinho da luta de classes internacional, numa crise sem precedente; um proletariado, minoria num país de camponeses, mas extremamente concentrados nas plantas industriais; uma burguesia russa débil, amesquinhada e tíbia, premida entre um proletariado - jovem, mas capaz de lutas e greves que levaram o mundo a conhecer a greve geral de massa - e o imperialismo. Um partido forjado e temperado em décadas de lutas na clandestinidade, semiclandestinidade, luta parlamentar, luta sindical, trabalho político nas forças armadas, exílios, prisões; líderes da estatura intelectual e 
política de Lenin, Bukarin, Kamenev, Zinoviev, Sverdlov, Trotsky, que irá se integrar ao partido bolchevique assim como a interdistrital, organização que fazia parte como líder. Esses são os componentes que levaram a primeira revolução socialista da História ao êxito.

\section{PARTIDO, REVOLUÇÃO E O FIM DA URSS}

O partido de Lenin foi a alavanca que permitiu a classe trabalhadora mover a Rússia e o mundo. Dizer isso não é de menor importância porque está na moda a defesa de um espontaneísmo ingênuo, a defesa do horizontalismo e se, não o fim da forma partido, mas a sua subalternização. Tal formulação, no mínimo, desconhece a polêmica travada contra os populistas russos, contra o marxismo legal, contra o cretinismo eleitoral, as ilusões constitucionais e também contra o abstencionismo esquerdista e a defesa da ofensiva permanente. É retomar uma visão que separa de forma liberal a luta política da luta sindical e de massas e não vê os limites da consciência tradeunionista. A passagem da classe em si para classe para si, da classe cônscia dos seus interesses históricos, exige o concurso de um programa e este significa um partido que centralize a luta da classe trabalhadora tornando-a classe dirigente e dominante por meio da revolução socialista.

Tornou-se comum acreditar que o partido de Lenin foi o demiurgo do processo de burocratização da revolução. Lenin não pensava em governar sozinho, os socialistas revolucionários e os mencheviques preferiram ficar do lado da contrarrevolução que da revolução. Em nenhum escrito dos principais líderes do partido bolchevique há a defesa do regime de partido único como quintessência do socialismo, da transição ou da coletivização forçada dos camponeses, da exaltação do atraso ou a repressão à liberdade artística como pedra angular do socialismo. Pelo contrário, Lenin (2007) escreveu a obra O Estado e a Revolução na qual defende que o socialismo é a auto-organização da classe trabalhadora.

Se os governos surgidos com a revolução de fevereiro tivessem retirado a Rússia da guerra ou tivessem feito a reforma agrária, seria pouco provável que os bolcheviques tivessem feito a revolução. Os bolcheviques a fizeram porque estes foram o elemento catalizador e de direção de um caudal de insatisfação que dormitava na sociedade russa e que eclodiu.

Caio Prado Jr (1978), um dos nossos grandes intelectuais marxista, escreveu que confundem a revolução com o momento de ruptura, de explosão, mas a revolução é também um longo processo que vai movendo as placas tectônicas e que permitem que as grandes 
transformações possam acontecer. É a velha toupeira que vai de forma cega fazendo seu trabalho de escavar os alicerces do edifício social possibilitando que o novo surja.

"Revolução" em seu sentido real e profundo significa o processo histórico assinalado
por reformas e modificações econômicas, sociais e políticas sucessivas, que,
concentradas em período histórico relativamente curto, vão dar em transformações
estruturais da sociedade, e em especial das relações econômicas e do equilíbrio
recíproco das diferentes classes e categorias sociais. O ritmo da história não é
uniforme. Nele se alternam períodos ou fases de relativa estabilidade e aparente
imobilidade, com momentos de ativação da vida político-social e bruscas mudanças
em que se alteram profunda e aceleradamente as relações sociais. Ou mais
precisamente, em que as instituições políticas, econômicas e sociais se remodelam a
fim de melhor se ajustarem e melhor atenderem a necessidades generalizadas que
antes não encontravam devida satisfação. São esses momentos históricos de brusca
transição de uma situação econômica, social e política para outra, e as transformações
que então se verificam, que constituem o que propriamente se há de entender por
"revolução" (PRADO JR., 1978, p. 11-12).

A guerra manifestou uma das principais contradições do capitalismo atual que é o do antagonismo entre estados nacionais e o mercado mundial. Essa contradição também se expressou na crise de 1929 que levou o mundo a uma nova disputa — entre as grandes potências — provocando a Segunda Guerra Mundial.

O legado da Revolução de Outubro de 1917 foi que a URSS impediu que o nazismo vencesse a guerra e que o mundo se tornasse um imenso campo de concentração, e a ameaça vermelha obrigou a burguesia europeia a criar o Estado do Bem Estar-Social. Não foi à toa que, logo após o debacle da URSS, o neoliberalismo recebeu ampla acolhida da burguesia internacional tornando-a política de governo e de Estado, destruindo direitos sociais, privatizando empresas estatais, assenhorando-se do fundo público e impondo uma tributação regressiva, a tal ponto que, hoje, oito multimilionários detêm uma riqueza equivalente a metade da população mundial. Nunca o Estado capitalista esteve tão próximo à frase lapidar de Marx e Engels: que o Estado capitalista não passa de um comitê da burguesia para gerir seus negócios. Não foi o socialismo que fracassou. É o capitalismo que não consegue satisfazer os anseios mínimos da população mundial.

Nenhum analista com apego aos sovietes conseguiu prever a derrocada da URSS, o que demostra a reduzida capacidade analítica desses intelectuais movidos não pela busca da verdade, mas para servir aos interesses do chamado "mundo livre". A Guerra Fria e o Plano Marshall foram dois componentes fundamentais para criação da arquitetura mundial que permitiu ao capitalismo o chamado trinta anos gloriosos e a supremacia estadunidense. $\mathrm{O}$ discurso de Churchill em Foulton, no Missouri, foi a oficialização da Guerra Fria servindo para ofuscar a imensa simpatia que os povos do mundo todo tinham pela URSS e pelo papel que 
cumpriu na Segunda Guerra e, servir de pretexto para perseguir o movimento socialista e democrático.

A política da burocracia ao defender a URSS colocando seus interesses, de camada privilegiada, acima da revolução internacional solapava as conquistas da revolução de Outubro: a saúde e educação pública, o monopólio do comércio exterior, a nacionalização da terra, o enorme desenvolvimento das forças produtivas que levou a URSS a vencer o nazismo, apesar do stalinismo, e a lançar o primeiro satélite no espaço em 1957. É lugar comum hoje dizer que nada funcionava e que a Rússia pagou um preço alto por querer saltar as leis do mercado, mas Galbraith (1988), insuspeito de ser esquerdista, esteve na URSS e disse que a economia funcionava muito bem.

Trotsky (1977), em 1936, escreveu que o estalinismo com seus planos irreais e superdimensionados, a ausência de um planejamento democrático e de uma política internacionalista, que levasse a classe trabalhadora a desconfiar de suas burguesias e privilegiar os interesses nacionais acima dos interesses da revolução internacional - que teve como corolário a tese do socialismo em um só país - levava à pavimentação da restauração do capitalismo na URSS porque de camada privilegiada, sedenta por prebendas e sinecuras, passaria a querer estabilizar seu domínio convertendo-se em classe dominante. Se uma teoria mostrou sua capacidade de predição diante das outras, essa foi o marxismo revolucionário, pois soube explicar com maior acuidade a revolução de Outubro e a URSS.

\section{CONCLUSÃO}

Da Revolução de Outubro podemos e devemos extrair lições históricas para a América Latina. Uma delas é que, abandonar os objetivos socialistas acaba levando ao abandono, inclusive, das bandeiras democráticas e que, somente um governo dos trabalhadores que exproprie a burguesia poderá realizar a contento essas bandeiras.

Assim como os bolcheviques ousaram e mostraram o caminho, os cubanos em 1959 desafiaram os Estados Unidos. A América Latina está numa encruzilhada, ou a reversão colonial com o seu cortejo de desindustrialização, retrocesso econômico e político ou a revolução socialista.

O nacionalismo da década de 50 e 60, do século passado, fracassou. Assim como a experiência atual dos governos nacionalistas moderados e de frente-popular que fizeram reformas em alguns aspectos importantes, mas deixaram intacto o poder do imperialismo. Não promoveram reformas de vulto que tocassem na questão fundiária, na enorme concentração de 
riquezas em nosso continente, não atacaram a questão da dívida pública, o controle que o capital estrangeiro exerce sobre a nossa economia e mantiveram o aparato repressivo e genocida herdado dos regimes militares. Essas tarefas e o sonho de uma América Latina unificada saíram definitivamente das mãos de nossa lumpenburguesia, parafrasendo Jorge Beinstein (2010), e só serão alcançadas com a unidade dos trabalhadores e de suas lutas.

\section{REFERÊNCIAS}

AMIN, Samir. Geopolítica do imperialismo contemporâneo. In: BORON, Atilio A. (Org). Nova hegemonia mundial: alternativas de mudança e movimentos sociais. Buenos Aires: Consejo Latinoamericano de Ciencias Sociales, 2004.

BEINSTEIN, J. Serra contra o Mercosul: o auge das direitas loucas na América Latina. Carta Maior, 2010. Disponível em: <https://www.cartamaior.com.br/?/Editoria/Internacional/Serracontra-o-Mercosul-o-auge-das-direitas-loucas-naAmericaLatina\%25250D\%25250A/6/15507>. Acesso em: 20 set. 2018.

GALBRAITH, John Kenneth. A economia e o interesse público. São Paulo: Editora Pioneira, 1988.

GRAMSCI, A. Escritos políticos. Vol. 2: 1921-1926. Rio de Janeiro: Civilização Brasileira, 2004.

LENIN, V. I. Teses de abril. Lisboa: Edições Avante!, 1978.

LENIN, V. I. O estado e a revolução. São Paulo: Expressão Popular, 2007.

LUXEMBURGO, R. O que quer a liga spartakus?. In: A revolução russa. Petrópolis: Voezes, 2005.

MARX, K. O 18 de Brumário de Luís Bonaparte. São Paulo: Boitempo, 2011.

MARX, Karl; ENGELS, Friedrich. Manifiesto del partido comunista. Madri: Mestas Ediciones, 2007.

PRADO JUNIOR, Caio. A revolução brasileira: perspectivas em 1977. 6 ed. São Paulo: Editora Brasiliense, 1978

TROTSKY, L. A história da revolução russa. Rio de Janeiro, Paz e Terra, 1977.

WEBER, M. Soziologie. Universalgeschichtliche Analysen. Politik. Stuttgart, Kröner 1973. 